Check for updates

AUTHOR:

J. Francis Thackeray ${ }^{1}$ iD

AFFILIATION:

${ }^{1}$ Evolutionary Studies Institute, University of the Witwatersrand, Johannesburg, South Africa

\section{CORRESPONDENCE TO:} Francis Thackeray

EMAIL:

mrsples@global.co.za

\section{HOW TO CITE:}

Thackeray JF. Morphometric ('log sem') analysis of anatomical measurements of Galápagos finches (Geospiza), chimpanzees (Pan) and Plio-Pleistocene hominins (Paranthropus, Australopithecus and early Homo). S Afr J Sci. 2022:118(1/2), Art. \#11913. https:// doi.org/10.17159/sajs.2022/11913

ARTICLE INCLUDES:

$\square$ Peer review

$\square$ Supplementary material

\section{KEYWORDS:}

morphometrics, Galápagos, Darwin, Finch, chimpanzee, Pan, hominin, Plio-Pleistocene

\section{PUBLISHED:}

27 January 2022
(C) 2022. The Author(s). Published under a Creative Commons Attribution Licence.

\title{
Morphometric ('log sem') analysis of anatomical measurements of Galápagos finches (Geospiza), chimpanzees (Pan) and Plio-Pleistocene hominins (Paranthropus, Australopithecus and early Homo)
}

\begin{abstract}
Significance:
- The 'log sem' morphometric method can be shown to be justified in the context of its use in the analysis of anatomical measurements of three sets of data: Galápagos finches (six species of Geospiza); two species of chimpanzees (Pan troglodytes and P. paniscus); and three hominin genera (Australopithecus, Paranthropus and early Homo).
\end{abstract}

A morphometric method has been used in analyses of linear measurements obtained from crania of modern hominoids ${ }^{1-3}$ as well as Plio-Pleistocene hominins, ${ }^{1,4,5}$ based on pairwise comparisons associated with least squares linear regression to quantify the degree of scatter around a regression line of the form $y=m x+c$, where $\mathrm{m}$ is the slope and $\mathrm{c}$ is the intercept. The log-transformed standard error of the m-coefficient, known as 'log sem', serves to quantify the degree of scatter around the regression line, associated with the degree of variability in shape. The effect of size is associated with the m-coefficient.

For many taxa, a mean log sem value of -1.61 has been recognised as a typical degree of intraspecific morphological variation in extant species. ${ }^{2,3}$ With a standard deviation of 0.1 , it has been used as a frame of reference for assessing probabilities of conspecificity when pairs of specimens are compared (e.g. Thackeray and Dykes ${ }^{3}$ and Thackeray ${ }^{4}$ ).

In this analysis, the results of an UPGMA (unweighted pair group method with arithmetic mean) cluster analysis were obtained from log sem statistics calculated from anatomical measurements from the following three sets of data as examples of method: Galápagos finches (Geospiza), chimpanzees (Pan troglodytes and P. paniscus), and Plio-Pleistocene hominins (Australopithecus africanus, A. sediba, Homo habilis, H. erectus, H. rudolfensis and $H$. naledi). The objective was to demonstrate that the log sem statistic has biological significance, reflecting variability in shape in a diversity of taxa.

\section{UPGMA tree for six species of Galápagos ground finches}

Using UPGMA, a log sem matrix was analysed for the six generally accepted species of ground finches, namely Geospiza magnirostris, G. fortis, G. fulginosa, G. difficilis, G. conirostris and G. scandens. ${ }^{6,7}$ The log sem matrix was based on measurements of the lengths of wing, tail, culmen, gonys, depth of bill at base, width of mandible at base, tarsus and middle toe with claw, from a database compiled by the California Academy of Sciences. Measurements were obtained from 36 specimens (an equal number of male and female specimens) resulting in more than 1200 regressions. A computer program for analysing large data sets (https://github.com/chdwck9/ professorRegressor) was used to calculate log sem statistics. ${ }^{8}$

Figure 1 presents the resulting phenetic tree. This tree corresponds closely to a phylogeny obtained by Burns et al. ${ }^{9}$ and Reaney et al. ${ }^{10}$ based on genetic data.

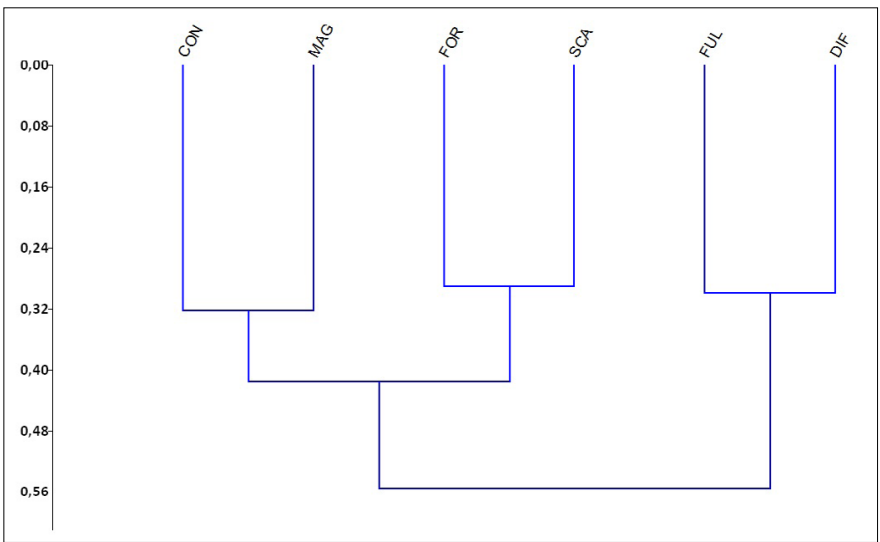

Figure 1: Results of a UPGMA analysis of a log sem matrix based on anatomical measurements of six species of Galápagos ground finches, namely Geospiza magnirostris (MAG), G. fortis (FOR), G. fulginosa (FUL), G. difficilis (DIF), G. conirostris (CON) and G. scandens (SCA). The phenetic tree corresponds closely with a phylogeny presented by Burns et al..$^{9}$ and Reaney et al., ${ }^{10}$ based on genetic data. Measurements were obtained from the California Academy of Sciences. 


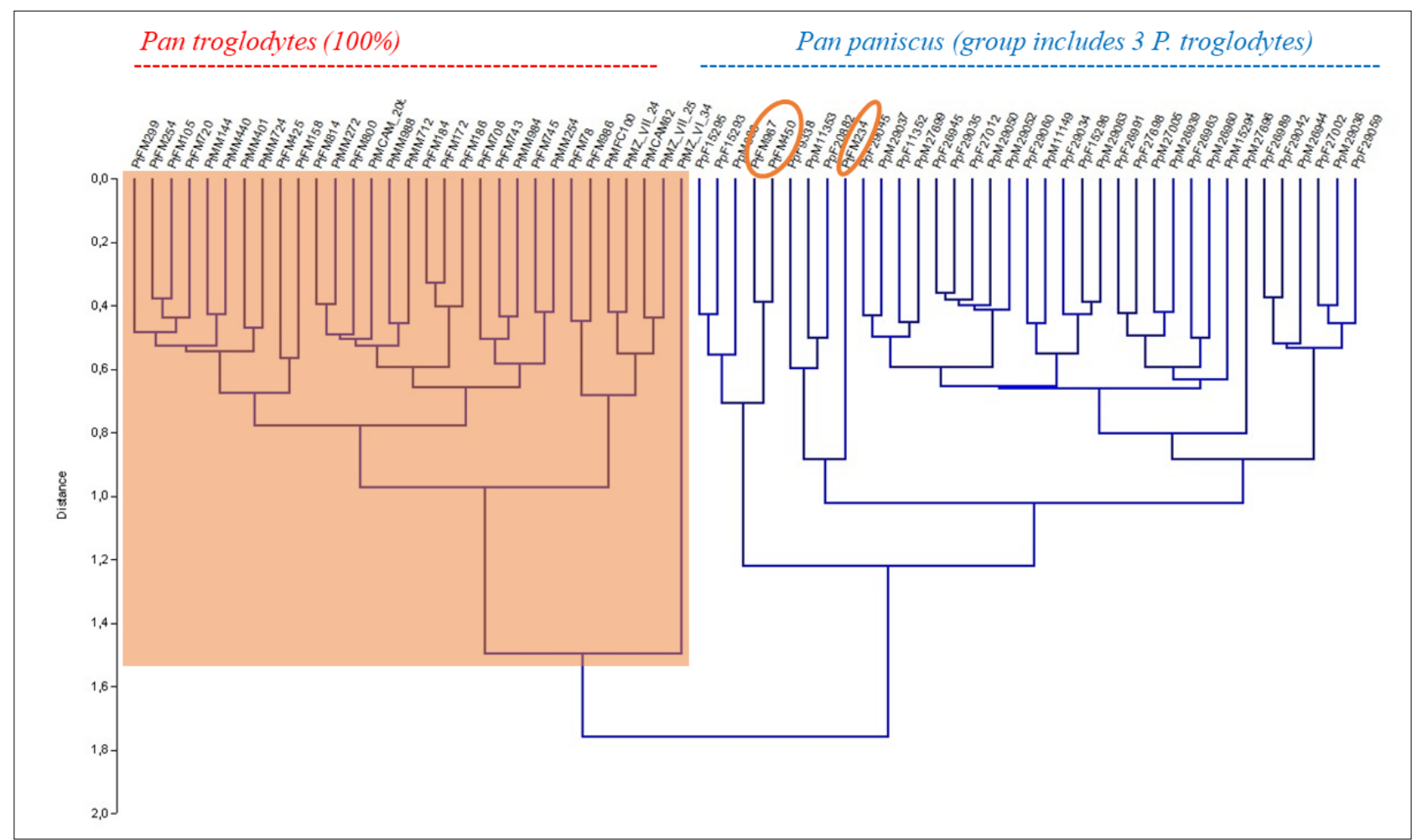

Figure 2: Phenetic tree obtained from UPGMA cluster analysis of log sem statistics based on pairwise linear regression analyses of cranial measurements of two chimpanzee species, Pan troglodytes ( $n=38$ specimens) and $P$. paniscus ( $n=38$ specimens). Measurements for specimens numbered here have been published by Gordon and Wood ${ }^{11}$. Log sem statistics generally distinguish between the two taxa.

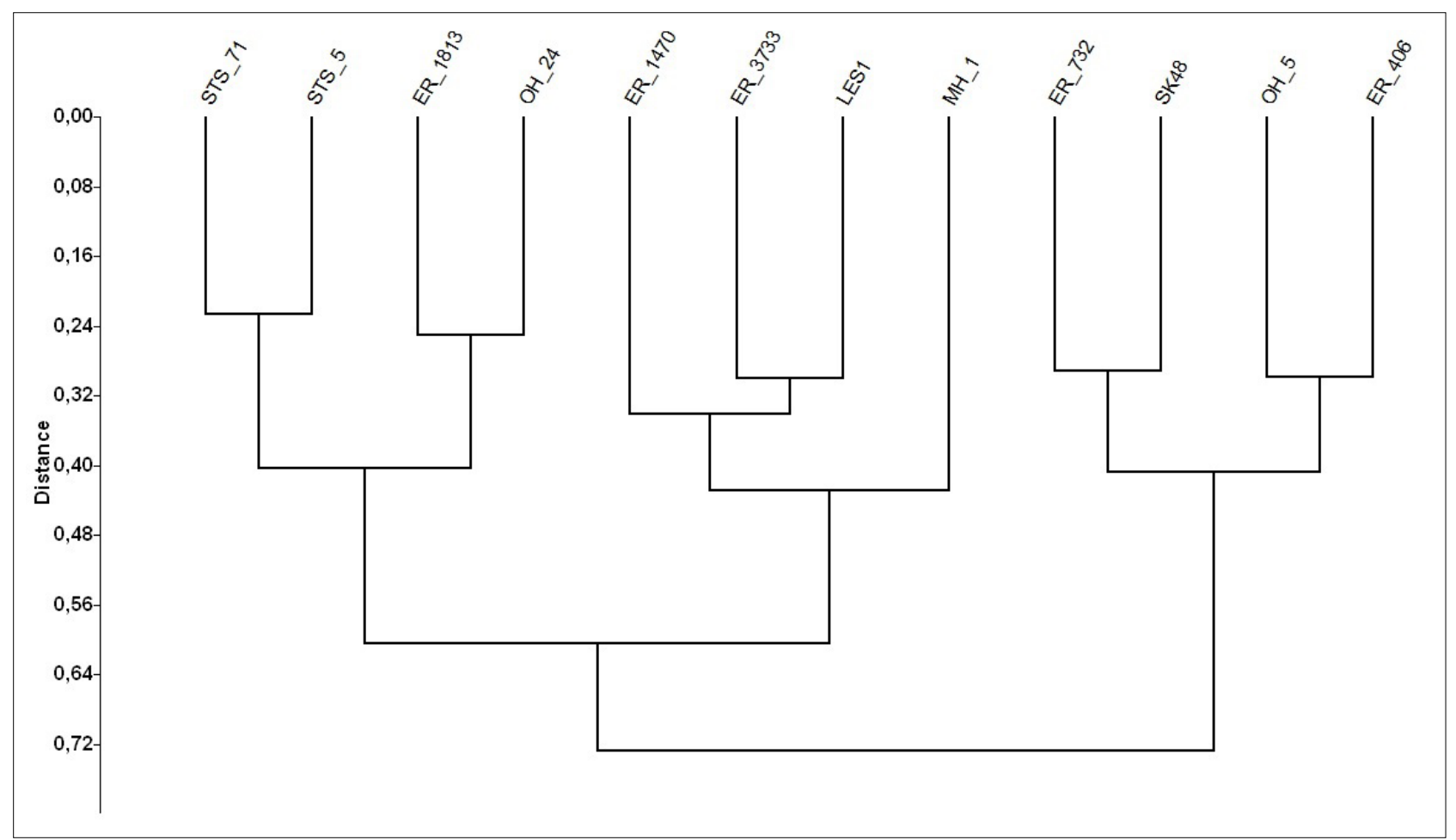

Figure 3: $\quad$ Phenetic tree obtained from UPGMA cluster analysis of log sem statistics based on pairwise linear regression analyses of cranial measurements of Plio-Pleistocene hominins, using measurements published primarily by Wood ${ }^{14}$. Three general groups are distinguished, whereby specimens attributed to Paranthropus are distinct from others attributed to Australopithecus and Homo. Sts 5 and Sts 71 are specimens of Australopithecus from Sterkfontein, South Africa. KNM-ER 1813 (Turkana Basin, Kenya) and OH 24 (Olduvai Gorge, Tanzania) have been attributed to $H$. habilis but group with $A$. africanus. KNM-ER 1470 (H. rudolfensis) and KNM-ER 3733 (H. ergaster) are both from the Turkana Basin. South African specimens LES 1 (H. naledi) and MH 1 (A. sediba) are from Rising Star and Malapa Caves, respectively. KNM-ER 406 and KNM-ER 732 are specimens of Paranthropus boisei from the Turkana Basin. The latter species is also represented by $\mathrm{OH} 5$ from Olduvai Gorge. SK 48 represents P. robustus from Swartkrans, South Africa. 


\section{UPGMA tree for two chimpanzee species}

Figure 2 presents a phenetic tree obtained from UPGMA cluster analysis of log sem statistics based on pairwise linear regression analyses of $P a n$ troglodytes and $P$. paniscus cranial measurements $(n=68$ specimens, more than 4500 regressions), using measurements published as supplementary material by Gordon and Wood ${ }^{11}$. The log sem approach generally distinguishes the two taxa, reflecting robusticity of the log sem method. Although 3 out of 34 specimens attributed to $P$. troglodytes group with others attributed to the closely related $P$. paniscus, this lack of a clear boundary is consistent with genetic evidence of hybridisation between chimpanzees and bonobos within the last million years. ${ }^{12,13}$

\section{UPGMA tree for Plio-Pleistocene hominin specimens}

Figure 3 presents a phenetic tree obtained from UPGMA cluster analysis of log sem data of the kind published by Thackeray and $0 \operatorname{des}^{5}$, generated from pairwise comparisons of Plio-Pleistocene hominin specimens attributed to Australopithecus, early Homo and Paranthropus, using measurements published by Wood ${ }^{14}$, with the addition of log sem data associated with $A$. sediba ${ }^{15}$ and $H$. naledi ${ }^{16}$.

Specimens attributed to $A$. africanus (Sts 71 and Sts 5 ) from South Africa and specimens attributed to $H$. habilis (KNM-ER 1813 and $\mathrm{OH} 24$ ) from East Africa form a group, consistent with the view that these are closely related. A log sem value of -1.51 calculated from a comparison between $\mathrm{OH} 24$ and Sts 5, combined with a so-called delta $\log \mathrm{sem}^{3}$ value of only 0.003 , points to a relatively high probability of conspecificity, despite the fact that $\mathrm{OH} 24$ from Olduvai Gorge in Tanzania has generally been attributed to $H$. habilis whereas Sts 5 ('Mrs Ples' from Sterkfontein in South Africa) is accepted as a specimen representing $A$. africanus. Wood and Collard ${ }^{17}$ proposed that $H$. habilis should instead be considered as A. habilis. Thackeray ${ }^{18}$ suggested that the transition between $A$. africanus and $H$. habilis may constitute a chronospecies.

Robust australopithecines (Paranthropus), including specimens SK 48, $\mathrm{OH}$ 5, KNM-ER 406 and KNM-ER 732, are separated as a group distinct from specimens attributed to $A$. africanus and others attributed to Homo, including $H$. ergaster (KNM-ER 3733) and $H$. rudolfensis (KNMER 1470). MH 1 (A. sediba, described by Berger et al..$^{15}$ as a 'Homolike australopith') groups with specimens attributed to Homo. Despite differences in age, LES 1 (H. naledi) groups with $H$. ergaster.

\section{Conclusion}

The three UPGMA analyses of log sem data, calculated for Galápagos finches (Geospiza), chimpanzees (Pan) and Plio-Pleistocene hominins (Paranthropus, Australopithecus and early Homo) reflect groups that have biological significance, serving at the same time to demonstrate that the log sem morphometric method has merit, based on anatomical measurements using landmarks.

\section{Acknowledgements}

This research was supported by the National Research Foundation (South Africa). I am grateful to the late Sue Dykes, Richard Dykes, Caitlin Schrein and Julien Benoit for their roles in the use of the log sem morphometric method. Anatomical measurements of Darwin's finches used in this study are from collections of Geospiza in the California Academy of Sciences, with the assistance of Moe Flannery. I thank Peter and Rosemary Grant, Arkhat Abzanhov, Ashley Reaney, Jack Dumbacher, Bob Zink, Tim Crowe, Marine Cazenave, Clément Zanolli, Peter KnoxShaw and an anonymous reader for comments and encouragement in relation to this study. I dedicate this paper to Sue Dykes.

\section{References}

1. Thackeray JF, Bellamy CL, Bellars D, Bronner G, Bronner L, Chimimba C, et al. Probabilities of conspecificity: Application of a morphometric technique to modern taxa and fossil specimens attributed to Australopithecus and Homo. S Afr J Sci. 1997;93:195-196.

2. Thackeray JF. Approximation of a biological species constant? S Afr J Sci. 2007;103:489.
3. Thackeray JF, Dykes S. Morphometric analyses of hominoid crania, probabilities of conspecificity and an approximation of a biological species constant. HOMO J Comp Hum Biol. 2016;67(1):1-10. http://doi:10.1016/j. jchb.2015.09.003

4. Thackeray JF. Alpha and sigma taxonomy of Pan (chimpanzees) and PlioPleistocene hominin species. S Afr J Sci. 2018;114(11/12), Art. \#a0291. https://doi.org/10.17159/sajs.2018/a0291

5. Thackeray JF, Odes E. Morphometric analysis of early Pleistocene African hominin crania in the context of a statistical (probabilistic) definition of a species. Antiquity. 2013;87. http://antiquity.ac.uk/projgall/thackeray335/

6. Grant PR, Grant BR. How and why species multiply: The radiation of Darwin's finches. Princeton, NJ: Princeton University Press; 2008. https:// doi.org/10.1515/9781400837946

7. Grant PR, Grant BR. 40 years of evolution: Darwin's finches on Daphne Major Island. Princeton, NJ: Princeton University Press; 2014. https://doi. org/10.1515/9781400851300

8. Dykes SJ, Dykes RD. 'Professor Regressor': A computer programme for rapid processing of large sets of data for pairwise regression analyses in palaeontological contexts. Palaeontol Afr. 2015;49:53-59. https:// wiredspace.wits.ac.za/handle/10539/17371

9. Burns KJ, Shultz AJ, Title PO, Mason NA, Barker FK, Klicka J, et al. Phylogenetics and diversification of tanagers (Passeriformes: Thraupidae), the largest radiation of Neotropical songbirds. Mol Phylogenet Evol. 2014;75:41-77. https://doi.org/10.1016/j.ympev.2014.02.006

10. Reaney AM, Bouchenak-Khelladi Y, Tobias JA, Abzhanov A. Ecological and morphological determinants of evolutionary diversification in Darwin's finches and their relatives. Ecol Evol. 2020;10(24):14020-14032. https:// doi.org/10.1002/ece3.6994

11. Gordon AD, Wood BA. Evaluating the use of pairwise dissimilarity metrics in paleoanthropology. J Hum Evol. 2013;65:465-477. https://doi.org/10.1016/j. jhevol.2013.08.002

12. De Manuel M, Kuhlwilm M, Frandsen P, Sousa VC, Desai T, Prado-Martinez J, et al. Chimpanzee genomic diversity reveals ancient admixture with bonobos. Science. 2016;354(6311):477-481. https://doi.org/10.1126/science. aag2602

13. Thackeray JF, Schrein CM. A probabilistic definition of a species, fuzzy boundaries and 'sigma taxonomy'. S Afr J Sci 2017;113(5/6), Art. \#a0206. https://doi.org/10.17159/sajs.2017/a0206

14. Wood BA. Koobi Fora Research Project. Volume 4: Hominid cranial remains. Oxford: Clarendon Press; 1991.

15. Berger LR, De Ruiter DJ, Churchill SE, Schmid P, Carlson KJ, Dirks PHGM, et al. Australopithecus sediba: A new species of Homo-like australopith from South Africa. Science. 2010;328:195-204. https://doi.org/10.1126/ science. 1184944

16. Berger LR, Hawks J, De Ruiter DJ, Churchill SE, Schmid P, Delezene LK, et al. Homo naledi, a new species of the genus Homo from the Dinaledi Chamber, South Africa. eLife. 2015;4, e09560, 35 pages. https://elifesciences.org/ articles/09560

17. Wood BA, Collard M. The changing face of the genus Homo. Evol Anthropol. 1999;8:195-207. https://doi.org/10.1002/(SICI)15206505(1999)8:6<195::AID-EVAN1>3.0.C0;2-2

18. Thackeray JF. Homo habilis and Australopithecus africanus, in the context of a chronospecies and climatic change. In: Runge R, editor. Changing climates, ecosystems and environments within arid southern Africa and adjoining regions. Palaeoecology of Africa 33. Leiden: CRC Press; 2015. p. 53-58. 